\title{
Sexual contact between doctors and patients
}

\author{
Almost always harmful
}

All codes of medical practice, ancient and modern, explicitly forbid a doctor to have sex with a patient. The General Medical Council forbids "improper relationships" or "indecent behaviour," while the American Medical Association states that "sexual activity with a patient is unethical." The American Psychiatric Association extends this sanction to include "ex-patients," believing that relationships with former patients are likely to exploit emotions deriving from treatment.

Despite such unambiguous ethical and legal declarations several sources suggest that violations are not uncommon. In a survey of 1442 north American psychiatrists, $7 \%$ of male and $3 \%$ of female respondents acknowledged having had sexual contact with their own patients. ${ }^{1}$ Similar figures have been reported for psychologists ${ }^{2}$ and psychotherapists. ${ }^{3}$ The problem, however, is not confined to those working in mental health. Kardener and colleagues reported that $18 \%$ of obstetricians, $13 \%$ of general practitioners, and $12 \%$ of internists confessed to or condoned sexual contact with their patients. ${ }^{+}$ A survey of Dutch gynaecologists and ear, nose, and throat specialists published in this issue found that $4 \%$ of respondents in each group reported a history of sexual contact with a patient ( $\mathrm{p} \mathrm{1531}$ ), suggesting that this is not only a north American phenomenon.

To be attracted to a patient is a common experience, acknowledged by $86 \%$ of male and $52 \%$ of female trainee psychiatrists in the United States ${ }^{1}$ and $84 \%$ of male and $27 \%$ of female gynaecologists in the Dutch study. ${ }^{5}$ It may not always be clear why some doctors are unable or unwilling to maintain the boundaries dictated by the established ethical, professional, and clinical codes of practice, but several risk factors can be identified.

In some cases it may be a conscious predatory desire to take advantage of their powerful position that leads doctors deliberately to exploit vulnerable patients. In other cases, boundary violations by clinicians may be an early symptom of psychiatric disorders, such as hypomania. Certain specialties may also be a greater risk, including psychiatry and gynaecology, which necessitate the most extreme invasions of the patient's physical or emotional privacy. Anecdotal accounts also suggest that the isolated middle aged practitioner who has experienced a mid-life crisis such as bereavement or separation may also be at risk of forming inappropriate relationships with patients. ${ }^{6}$

Certain patients also seem to be at increased risk of fostering a sexual relationship with their doctor, including those with dependent or submissive personalities, and people with more profound personality disturbances who have difficulty defining or accepting psychological and social boundaries. $^{7}$ The victims of sexual abuse or neglect in childhood may continue to sexualise future relationships with important figures including the doctor. In these cases it may not be the individual doctor who is attractive but what the doctor represents in the patient's internal world. Similar psychological vulnerabilities on the doctor's part may lead him or her to initiate or respond to inappropriate erotic overtures.

For the patient the overwhelming evidence is that sexual contact with the doctor is seriously harmful. ${ }^{38}$ In one survey $65 \%$ of American psychiatrists had treated patients who had been sexually involved with previous therapists; this was considered to be harmful to the patient in $87 \%$ of cases. ${ }^{9}$ This is in keeping with doctors' own reports of sexual contact with their own psychotherapists, which is nearly always described as being damaging. ${ }^{10}$ In addition, the long term consequences of sexual assault in children and adults are being increasingly recognised. "12 Despite these results there is a marked tendency for offenders to rationalise their behaviour and minimise the potential harm to the patient. ${ }^{1} 3^{9}$ The effects for the doctor may also be serious, including suspension of medical registration, criminal proceedings, and public humiliation.

The management of dysfunctional patient-doctor relationships must first address the immediate needs of the victim, but this may be hampered by the reluctance of victims to come forward to therapeutic agencies at the time of abuse. This may be because patients do not necessarily view the sexual aspect of the relationship as a problem or because of feelings of shame or fear. For obvious reasons the offending doctor is often reluctant to come forward. More important is the reluctance of third party doctors to report cases that have come to their attention, ${ }^{9}$ probably reflecting uncertainty about the value of reporting, concern to protect the patient's confidentiality,,$^{13}$ and a failure to trust patients' accounts of their experiences.

Some American states have taken this dilemma out of doctors' hands by passing legislation which obliges therapists to report cases where they suspect previous sexual involvement. Statutes also exist making sexual contact with patients a crime and which make it easier to sue offending therapists, and consequently encourage reporting by patients. ${ }^{1+}$ This in part reflects a lack of confidence in the internal disciplinary 
procedure of the profession. More positively, this offers help to patients who may be abused by practitioners, including unlicensed psychotherapists and practitioners of alternative medicine, who may not be bound by codes of practice or internal disciplinary procedures.

Once cases do come to light there should be help and compensation for the victim. Patients should be treated outside the setting in which the original abuse occurred. Victims should be allowed to ventilate feelings about their experience, which will include a complex mixture of anger, guilt, and sadness. The therapist should not attempt to shield professional colleagues from normal disciplinary procedures. In this context it is important for doctors, both individually and as a profession, publicly to take a clear stance on this matter so that patients can be sure that their complaints are taken seriously and dealt with effectively.

Management of the offender should combine a compassionate regard for their special needs, including counselling or psychiatric treatment, with implementation of the appropriate disciplinary measures. Deliberate misconduct demands strict censure and supervision of future clinical practice. This should reinforce public confidence, act as a deterrent to the exploitive offender, and encourage the sick to seek help.

The cornerstone of prevention of sexual contact between doctors and patients is education. Discussion of the subject could be appropriately included in undergraduate psychiatry and medical ethics courses. Doctors should also be able to discuss these issues with their supervisors or peers without fear of ridicule or persecution.

Clinicians can take steps to make it less likely that they will be drawn into an erotic relationship. ${ }^{6}$ Such steps will also reduce the risk of false accusations, which can be extremely damaging. Those working in hospital can most readily protect themselves by using chaperones when seeing patients and minimising social contact with patients. Setting limits on patient contact such as seeing patients only in the clinic, at appointed times, and with chaperones are impractical for those who have to offer emergency treatment at the patient's request. Furthermore, the recommendation that all social contact with patients should be avoided as it could be a precursor to frankly unethical activity is unrealistic for some practitioners. In such situations it is important to have a close working relationship with other health professionals. If a doctor becomes aware of professional boundaries being eroded then this should be discussed with colleagues, and possibly the care of the patient transferred to another clinician.

THOMAS FAHY

King's College Hospital and

Institute of Psychiatry,

London SE5

Lecturer in Psychological Medicine

Maudsley Hospital,

London SE5

1 Gartrell N, Herman J, Olarte S, Feldstein M, Localio R. Psychiatrist-patient sexual contact: results of a national survey, I: prevalence. Am $\mathcal{F}$ Psychiatry 1986;143:1126-31.

2 Holroyd JC, Brodsky AM. Psychologists' attitudes and practices regarding erotic and nonerotic physical contact with patients. Am Psychol 1977;32:843-9.

3 Bouhoustos J, Holroyd J, Lerman $\mathrm{H}$. Sexual intimacy between psychotherapists and patients. Professional Psychology: Research and Practice 1983;14:185-96.

4 Kardener SH, Fuller M, Mensh IN. A survey of physicians' attitudes and practices regarding erotic and non erotic contact with patients. Am f Psychiatry 1973;130:1077-81.

Wilbers D, Veenstra G, van de Wiel HBM, Schultz WCMW. Sexual contact in the doctor patien relationship in the Netherlands. BMF 1992;304:1531-4.

6 Benedek E. Intimacy with patients: it's always harmful. Psychiatric News 1990 July 6:3.

7 Gutheil TG. Borderline personality disorder, boundary violations, and patient therapist sex meil TG. Borderline personality disorder, boundary

medicolegal pifflls. Amg Pychy disorder, boun 1987,602 . health care practitioners and their clients. F Consult Clin Psychol 1984;52:1054-61.

Gartrell N, Herman J, Olarte S, Feldstein M, Localio R. Reporting practices of psychiatrists who knew of sexual misconduct by colleagues. Am J Orthopsychiatry 1987;57:287-95.

knew of sexual misconduct by colleagues. Am F Orthopsychiatry 1987;57:287-95.
Gartrell N, Herman J, Olarte S, Localio R, Feldstein M. Psychiatric residents' sexual contact with educators and patients: results of a national survey. Am J Psychiatry 1988;145:690-4.

11 Mullen PE, Romans-Clarkson SE, Walton VA, Herbison GP. Impact of sexual and physical abuse on women's mental health. Lancet $1988 ; \mathrm{i}: 841-5$.

12 Jacobsen A, Richardson B. Assault experiences of 100 psychiatric inpatients: evidence of the need for routine inquiry. Am f Psychiatry 1987;144:908-13.

13 Stone AA. Sexual misconduct by psychiatrists: the ethical and clinical dilemma of confidentiality. Am f Psychiatry 1983;140:195-7

14 Appelbaum PS. Statutes regulating patient-therapist sex. Hosp Community Psychiatry 1990; 41: 15-6.

\section{Living bone grafts}

\section{Cell culture may overcome the limitations of allografts}

Bone grafting is widely used in orthopaedics and maxillofacial surgery. ${ }^{1}$ Currently the ideal graft material is autologous cancellous bone, usually taken from the iliac crest, which provides living osteoblasts and may provide mechanical support. Its use, however, is hindered by morbidity at the donor site, which includes postoperative pain, infection, wound scarring, anaesthesia of the buttock, herniation of muscle, meralgia paraesthetica, subluxation of the hip, and prolongation of the hospital stay. ${ }^{24}$ Furthermore, the volume required often exceeds what is available, especially in children .

To overcome these difficulties alternative forms of graft material have been sought. These fall into two broad groups: bone preparations - both human and animal, mineralised and demineralised-and bioceramics, which are mainly composed of a combination of tricalcium phosphate and hydroxyapatite. Bioceramics include marine coral, which is currently being investigated. ${ }^{5}$

Human allografts provide mechanical strength but do not contain living osteoblasts; their use carries the risk of infection, although sterilisation should largely eliminate this. Fresh allografts provoke a vigorous inflammatory response and often rejection of the graft, ${ }^{1}$ although immunogenicity can be reduced by demineralising and freezing "treatments" of the material. Re-establishment of the blood flow, which is a vital step in incorporating a graft, is thought to be impaired in allogeneic grafts, and this inhibits the rate of formation of new bone and resorption of the graft. ${ }^{6}$

Demineralising allograft bone, as well as reducing immunogenicity, may expose a group of matrix growth factors known as the bone morphogenetic proteins. These cause the formation of bone in soft tissues by stimulating primitive mesenchymal cells to differentiate into osteoblasts - a process known as osteoinduction. ${ }^{7}$ Demineralised bone is therefore superior to untreated allograft because it has intrinsic bone forming ability, although it may have reduced mechanical strength. ${ }^{8}$

Recently, recombinant bone morphogenetic protein-2 has been shown to heal large segmental bone defects in dogs, but more extensive work, including studies in humans, is required. ${ }^{9}$ Using bone marrow aspirates to enhance both bioceramics and bone allografts has been another approach, ${ }^{10}$ which has so far met with only limited success. Bioceramics 